\title{
Fora de foco: uma análise da cobertura midiática sobre as pessoas em situação de rua ${ }^{1}$
}

\author{
Suzana ROZENDO ${ }^{2}$ \\ Criselli MONTIPÓ
}

\section{RESUMO}

Este artigo apresenta uma análise crítica à abordagem jornalística dos meios de comunicação de massa brasileiros quando os protagonistas dos fatos são pessoas em situação de rua. Busca-se, desta forma, evidenciar a humanização na narrativa jornalística e seu oposto: a desumanização dos relatos. O método adotado foi a análise de conteúdo. Para isso, analisamos algumas reportagens veiculadas na mídia em que é possível perceber a adoção de termos inadequados e a apuração descontextualizada.

Palavras-chave: Fundamentos do jornalismo; Humanização na narrativa jornalística; Pessoas em situação de rua, Rede Globo, Clarín.

\begin{abstract}
This article reports a critical journalistic approach to the Brazilian media when the reporters of the facts are homeless. The point of this article is to highlight the humanization of the media coverage, and also, the direct opposite: the dehumanization of the media coverage. The method adoted was the content analysis. In order to achieve this goal, we analyzed some reports that had been broadcasted by the media. Upon listening to them, one can see the adoption of inadequate terms and decontextualized coverages.
\end{abstract}

Key-words: Fundamentals of journalism, journalism humanization narrative's, Homeless, Rede Globo, Clarín.

\section{0 jornalismo na atualidade: os furos da instantaneidade informativa}

Com o crescente surgimento das novas tecnologias, a palavra de ordem é a instantaneidade informativa. Assim, os meios de comunicação noticiosos da atualidade

1 Trabalho apresentado à terceira edição da Revista Ação Midiática - Estudos em Comunicação, Sociedade e Cultura, publicação ligada ao Programa de Pós-Graduação em Comunicação e Sociedade, da Universidade Federal do Paraná. Parte deste trabalho foi apresentado no IX Encontro Paranaense de Pesquisa em Jornalismo, UEPG, em outubro de 2011.

${ }^{2}$ Mestre em Jornalismo pela Universidade Federal de Santa Catarina. sukirozendo@ hotmail.com

${ }^{3}$ Mestre em Jornalismo pela Universidade Federal de Santa Catarina. criselli@gmail.com 
enfrentam uma rotina cada vez mais acirrada em busca da informação. Muitos preferem publicar mais rápido a publicar melhor. $\mathrm{O}$ deadline e a comodidade de acesso aos meios para obtenção da informação têm afastado, por vezes, a essência humana dos relatos da mídia que, ao que tudo indica, dá mais atenção à narrativa carregada de números e estatísticas, sem conhecer de perto o cidadão que sofre ou que vence em um mundo não noticiado. Desta forma, este artigo visa a refletir sobre a cobertura jornalística dos meios de comunicação de massa brasileiros quando os protagonistas dos fatos são pessoas em situação de rua.

Vale lembrar, neste sentido, que desde seu surgimento, o jornalismo tem ocupado a responsabilidade de ser mediador do espaço público. Entretanto, Nelson Traquina já questionou: "Afinal, qual é o papel do jornalismo na sociedade - um campo aberto que todos os agentes sociais podem mobilizar para as suas estratégias comunicacionais ou um campo fechado a serviço do status quo?" (2004, p. 145).

Kovach e Rosenstiel (2004), em Elementos do Jornalismo, ressaltam que a primeira lealdade dos jornalistas é com os cidadãos. Entre tais elementos, destacam que o jornalismo deve abrir espaço para a crítica e o compromisso público, além de empenhar-se para apresentar o que é significativo de forma interessante, relevante, compreensível e proporcional, atuando como um monitor independente do poder.

Dessa forma, o relato jornalístico tem como pressuposto ser plural e democrático, pois pretende ser o espaço compartilhado para o qual os diferentes sujeitos sociais projetam seus discursos. Entretanto, Jorge Pedro Sousa (2002) esclarece que a produção jornalística resulta de um processo de construção em que estão em jogo fatores de natureza pessoal, social, ideológica, cultural, histórica e tecnológica que são difundidos pelos meios noticiosos (p. 13). Tal produção é resultado de um mosaico de processos, vozes e estilos que obedece aos mesmos moldes da existência que busca expressar: a complexidade do mecanismo social.

Diante disso, questionamos como o jornalismo contemporâneo tem relatado a vivência humana imbricada em sua complexidade. A ansiedade pelo furo jornalístico, amparado na instantaneidade informativa, tem dado conta da realidade complexa? Tal questionamento encontra seus indícios a alguns passos atrás na história da humanidade, mais especificamente no momento em que a imprensa incorpora a racionalidade e a eficiência do pensamento científico predominante e adota processos nos mesmos 
moldes de fabricação capitalista.

Os meios de comunicação, que vendem o produto chamado notícia, querem oferecer esse produto com agilidade, antes dos demais veículos. Esse procedimento leva a imprensa a realizar uma cobertura jornalística que não se atenta aos detalhes do fato, mas que seja fria e instantânea.

Cremilda Medina (2006) lembra que esse pensamento vigente se traduziu nas redações na forma de padronizações de procedimentos para a constituição de modelos praticados até hoje. Segundo a autora, os princípios funcional-positivistas inscritos na Modernidade impulsionaram práticas que incentivaram a separação entre o que é subjetivo e o que é objetivo, priorizando este último nos relatos jornalísticos e, com isso, diminuíram as possibilidades de contextualização e, portanto, de humanização dos fatos narrados.

\title{
2 Sobre a humanização na narrativa jornalística
}

É importante ressaltar que neste trabalho entende-se por narrativas humanizadas aquelas que priorizam um relato produzido com contexto, com vidas, com busca de múltiplas vozes e olhares. Ou seja, quando o jornalismo atende ao seu compromisso social: busca os fatos relevantes e os relata como histórias ricas em informações - que podem ser impressões, detalhes, sensações, emoções - com o intuito de subsidiar seu público para a formação de um conceito, uma posição sobre o assunto. Como acentua Ijuim (2011):

\begin{abstract}
O jornalismo humanizado produz narrativas em que o ser humano é o ponto de partida e de chegada, o que supõe que este fazer começa antes da pauta, na consciência do ser jornalista. Em seu trabalho de apuração, busca versões verdadeiras e não, necessariamente, produz a verdade, pois o repórter não se relaciona com um objeto de conhecimento, mas com outros seres humanos envolvidos no processo comunicativo. Dessa forma, sua busca envolve a compreensão das ações dos sujeitos da comunicação - é a expressão dos sentidos da consciência. Na procura da essência dos fenômenos, atribui-lhe significados, os sentidos, para proporcionar ao público, mais que a explicação, a compreensão das ações humanas (IJUIM, 2011, p. 17 - itálicos do original).
\end{abstract}

O autor enfatiza que em sua relação com o mundo, o jornalista esvazia-se de preconceitos de modo a captar, ver e enxergar, ouvir e escutar, questionar e sentir. 
"Munido de uma racionalidade criativa e da emoção solidária, assume uma postura de curiosidade e descoberta, de humildade para sentir as dores do mundo (Dines), de empatia, de solidariedade às dores universais (Medina)" (p. 17). Ijuim considera que, como consequência da adoção do relato humanizado, sua narrativa será a organização do que está disperso, com as ligações do que está desconexo, portanto, será rica em contexto que possa esclarecer, proporcionar compreensão. Além disso, poderá ficar isenta de prejulgamentos, de preconceitos e de estereótipos.

Portanto, obter esses resultados pressupõe que o comunicador se coloque como ser humano ético e consciente de sua responsabilidade, pois, antes de tudo, é um cidadão e um integrante da espécie humana. Para se chegar a essas narrativas, entretanto, é preciso sair dos lugares-comuns, do molde chamado lead, e tratar a informação de forma criativa e humanizada, com impressões e detalhes. Nesse aspecto, Chaparro (2004) ressalta que o relato humanizado é a ferramenta social para satisfazer não apenas a curiosidade das pessoas, mas o vácuo universal de noticiar o tempo e a existência humana, que vincula a comunicação, o jornalismo aos processos da vida e da cultura. É a forma de se perceber, nas manifestações do cotidiano, a complexidade dos problemas e, pelo relato, ligá-las aos valores da vida humana, rumo à transformação. "O resgate da cena viva exige a criação de um narrador que dramatize o que se passa à sua volta. Para isso, o autor da narrativa é um ser aberto aos demais códigos da experiência social que observa" (MEDINA, 2008, p. 98).

O relato humanizado também pode ser entendido como aquele que traz a figura humana sempre presente. Pode parecer redundante, mas, ao analisar a imprensa cotidiana, que teria como princípio noticiar a vida humana, percebe-se que nem sempre as pessoas das quais a matéria jornalística trata estão presentes. As rotinas profissionais da atualidade, muitas vezes, distanciam o repórter da cena viva, que, de certo modo, deveria ser seu habitat. Longe de seu espaço por excelência, a rua, muitos jornalistas acabam sucumbindo à hora de fechamento ou à comodidade dos relatórios (hoje, em grande medida, os digitais) e se esquecem de conversar, ver e até sentir a esfera das vidas que narram.

Fontcuberta e Borrat (2006) chamam a atenção para o potencial identitário dos meios de comunicação. 
Não podemos falar de identidade sem falar do conceito de alteridade. Para Gustafsson a alteridade pode ser usada em dois sentidos: primeiro em seu sentido ontológico da existência de algo outro, diferente, ou não idêntico, em comparação ao que é o mesmo que si; segundo, no da imagem que tem um sujeito (geralmente coletivo) de outro. Essa construção das imagens do outro hoje se realiza em grande parte através dos meios de comunicação (FONTCUBERTA e BORRAT, 2006, p. 76, tradução livre).

Desta forma, tamanha é a responsabilidade da mídia, já que ao gerar informação também cria consensos. García Canclini (2009) destaca que ao examinar os discursos e os trabalhos estatísticos dedicados aos excluídos, muitos autores observam que as desvantagens sociais são consideradas como uma consequência de relações entre miséria e culpa, ou de características facilmente transformáveis em fatores de responsabilidade individual, de modo que se elimina a questão estrutural da exploração ligada à noção de classe. "Agora, o mundo encontra-se dividido entre os que têm domicílio fixo, documento de identidade, cartão de crédito, acesso à informação e dinheiro, e, por outro lado, os que carecem de tais conexões" (GARCÍA CANCLINI, 2009, p. 92). O autor enfatiza que a relativa unificação globalizada dos mercados não se sente perturbada pela existência de diferentes e desiguais. E isso parece se refletir no relato jornalístico quando se trata de pessoas em situação de rua.

\section{As pessoas em situação de rua}

Quem são os homens e as mulheres que transformam as ruas em abrigo? Em "A difícil decisão de viver nas ruas", o repórter Diego Antonelli ${ }^{4}$ esclarece que são pessoas que por diversos motivos deixaram seus lares para tentar a sorte no espaço público. Estão acostumadas aos olhares indiferentes dos que passam, e carregam histórias tristes e conflituosas que, dificilmente, ganham voz no meio da multidão.

O repórter questiona: mas o que leva alguém a decidir viver ao relento, sem endereço fixo? "Um estudo inédito coordenado pelo doutor em Sociologia Lindomar

\footnotetext{
4 Disponível em: <http://www.gazetadopovo.com.br/vidaecidadania/conteudo.phtml?tl=1\&id=1251558\&tit=A-dificildecisao-de-viver-nas-ruas>. Acesso em: 12 maio 2012.
} 
Boneti, da Pontifícia Universidade Católica do Paraná (PUCPR), revela que são três as principais causas: conflitos familiares, desemprego e fracasso escolar" ${ }^{\prime}$.

A pesquisa ouviu, até o momento, 300 pessoas que vivem nas ruas da capital paranaense. Segundo estatísticas preliminares do Movimento Nacional de População de Rua, aproximadamente 10 mil pessoas residem nas ruas no Paraná - metade em Curitiba. No país, são quase 2 milhões. "[...] O senso comum aponta as drogas como um fator preponderante para que parte da população decida viver na rua, mas os especialistas afirmam que o vício é consequência e não causa" (Ibidem). A problemática não atinge apenas países em desenvolvimento. Em Nova York, nos Estados Unidos, por exemplo, o número de sem-teto chegou ao recorde de 43 mil em abril de 2012, sendo que, deste total, 17 mil eram crianças ${ }^{6}$.

Quando o assunto em pauta são as pessoas em situação de rua, são utilizadas diversas denominações nos setores da sociedade civil, do poder público e dos movimentos sociais. A grande imprensa costuma utilizar o conceito "morador de rua" e, portanto, é frequente nos depararmos com manchetes como "Morador de rua morre queimado no Juvevê", ou "Doze moradores de rua em AL já foram mortos este ano".

Em alguns casos, os relatos padecem da desumanização comunicativa, como podemos perceber na abordagem de fatos em que os jornalistas, em alguns veículos de comunicação, sequer divulgam o nome do personagem principal da história. Além disso, estes transmitem a impressão de que a pessoa em situação de rua é a única culpada por estar naquela condição de vida. As matérias, em geral, não nos levam a refletir sobre como é possível minimizar esta problemática crescente de pessoas que fazem do espaço público seus locais de moradia e trabalho e quais foram os motivos que levaram a isso. Para ilustrar o que estamos falando, analisamos a notícia "Homem é internado após levar 15 facadas em Belo Horizonte", veiculada em 22 de setembro de 2011, no site Globo.com, um dos mais acessados no Brasil:

\footnotetext{
5 Ibidem.

6 Disponível em: <http://www1.folha.uol.com.br/mundo/1102310-nova-york-atinge-recorde-de-43-milsem-teto-em-refugios.shtml>. Acesso em: 19 jun. 2012.

7 Disponível em: <http://www.paranaonline.com.br/editoria/policia/news/540982/?noticia=MORADOR+DE+RUA+MORRE+QUEIMADO+ NO+JUVEVE>. Acesso em: 11 set. 2011.

8 Disponível em: <http://www.estadao.com.br/noticias/geral,doze-moradores-de-rua-em-al-ja-forammortos-este-ano,709883,0.htm>. Acesso em: 11 set. 2011.

9 Disponível em: <http://g1.globo.com/minas-gerais/noticia/2011/09/homem-e-internado-apos-levar-15facadas-em-belo-horizonte.html>. Acesso em: 22 set. 2011.
} 
Um homem foi esfaqueado na noite desta quarta-feira (21) no bairro Funcionários, na Região Centro-Sul de Belo Horizonte. De acordo com a Polícia Militar (PM), a vítima seria um morador de rua e teria levado 15 facadas.

Ainda segundo a PM, o homem, que aparentava ter 30 anos, foi encontrado sem documentos próximo à Catedral de Nossa Senhora da Boa Viagem. Ele foi encaminhado para o Hospital de Pronto-Socorro João XXIII, na capital mineira. De acordo com a assessoria da unidade de saúde, o estado de saúde dele é grave, mas estável.

Ao finalizar a leitura, ficam algumas questões, a saber: qual o nome desse homem? Há quanto tempo ele estava na rua? Qual foi o motivo da agressão? Por que ele não tinha documentos? Abordagens como essa nos deixam a impressão de que essas pessoas, quando são noticiadas, exibem a dinâmica doentia desse corpo social esfacelado, causando ainda mais repulsa, depois de consumir a notícia, em quem já possui um preconceito sobre as pessoas de rua. "Esses retratos dinâmicos são oferecidos nos jornais nacionais televisivos como parte dos jantares de cidadãos que olham tudo atônitos e respiram aliviados quando o foco da emissora passa para cenas mais amenas" (ALVAREZ; ALVARENGA; FERRARA, 2004).

Christofoletti (2000), ao triangular os conceitos de jornalismo, verdade e ética, sublinha, com o devido destaque, que se:

de um lado, o público tem o dever de ser informado, de outro, o jornalista tem o dever de informar. Mas este compromisso de responsabilidade social só é exercitado na plenitude quando a informação recebe tratamento adequado, é repassada de forma criteriosa, tem vínculos que contribuem para a sua contextualização. Sem o estabelecimento de alguns elos com a sua realidade sócio-histórica, a informação fica solta no imaginário das pessoas, gratuita, passível de uma absorção despreocupada, apenas de forma acumulativa (p. 52).

Por isso, a forma com que esses indivíduos são apresentados pela mídia, muitas vezes, como no caso supracitado, nos faz criar representações mentais de um universo com o qual não temos contato diretamente, apesar de ser visível a olhares atentos. Seremos levados a pensar que um homem, que aparentava ter 30 anos, levou uma série de facadas ou porque provocou alguém, ou porque tinha uma dívida de drogas, ou 
simplesmente foi violentado porque não tinha como se proteger. Em resumo, pensamos nesse homem como violento, drogado ou "coitadinho".

Walter Lippmann (1997), na década de 1920, já dizia que as pessoas agem tendo em vista não a realidade que as cerca, mas "as imagens criadas em suas cabeças". As representações mentais sobre esse contingente são associadas à sujeira e a doenças, quando não à violência, à morte ou a massacres:

\begin{abstract}
O estereótipo do nômade urbano é clássico: roupa esfarrapada, pele encardida com dermatoses, às vezes abrindo em feridas, corpo marcado por cicatrizes; unhas das mãos e dos pés enegrecidas, compridas e, por vezes, deformadas; dentes em parte caídos, em parte cariados; cabelos ensebados, olhos congestionados, etc. São signos genéricos que contam a trajetória social e tornam evidente que o indivíduo faz parte da população pobre que habita as ruas (MAGNI, 1994, p. 134 apud MATTOS, 2006).
\end{abstract}

Mattos (2006) dedicou parte de seus estudos sobre esses personagens para criar um conceito diante da heterogeneidade do assunto. $\mathrm{O}$ autor salienta que as variadas denominações existentes para tratar essas pessoas estão relacionadas também com a variedade de formas de vivenciar a rua. Assim, o autor defende o uso de "pessoas em situação de rua" e explica o porquê estratificando as palavras, a começar por "pessoas", no plural, de maneira a destacar não só aquilo que as iguala, mas também o que as diferencia. O segundo termo analisado é "situação", que evidencia "o caráter transitório e passageiro da situação de rua como condição social" (MATTOS, 2006, p. 41) em detrimento de substantivos como "morador de rua", que nos passa a impressão de algo estático. Por fim, Mattos (2006) compreende o termo "rua" "como um lugar em um todo, numa relação dialética com a casa”, que se configura como local onde não há estabilidade, não há certa disposição de objetos e não há segurança.

Quando questionado sobre o uso de termos pejorativos para tratar da população de rua, o diretor e fundador da revista Ocas", vendida por pessoas em situação de vulnerabilidade econômica, em São Paulo e no Rio de Janeiro, concorda com Mattos (2006) na defesa do uso do termo e salienta a questão da realidade provocada:

A ideia é você não determinar que aquela pessoa é sempre de rua. Primeiro ela é uma pessoa, então já muda, na verdade ela está em uma situação transitória, não é da rua, ela não nasceu e não vai morrer na rua, ela está neste momento nesta situação e ela se transforma porque ninguém nasceu para morar na rua. A ideia é mostrar que essa realidade é uma realidade que foi provocada, não é eterna, ela não existia e ela pode deixar de existir. Então as pessoas que hoje estão em situação de rua são pessoas 
em situação de casa, elas podem morar numa casa. Quando eu falo morador de rua dá ideia de que a pessoa nunca vai sair de lá (COSTA. São Paulo: 17 de janeiro de 2011).

Nessa práxis podemos compreender que a situação de rua costuma ter um caráter processual e transitório, o que não se concretiza como uma condição permanente na vida do indivíduo, caracteriza-se mais como uma circunstância adversa e, na maioria das vezes, efêmera. Vieira, Bezerra e Rosa (1992) apontam três situações que permeiam a heterogeneidade da rua:

\begin{abstract}
A rua pode ter pelo menos dois sentidos: o de se constituir num abrigo para os que, sem recurso, dormem circunstancialmente sob marquises de lojas, viadutos ou bancos de jardim ou pode constituir em um modo de vida, para os que já têm na rua o seu habitat e que estabelecem com ela uma complexa rede de relações. Seria possível identificar situações diferentes em relação à permanência na rua: ficar na rua - circunstancialmente; estar na rua - recentemente; e ser da rua - permanentemente [...]. O que diferencia essas situações é o grau maior ou menor de inserção no mundo da rua (VIEIRA, BEZERRA, ROSA, 1992, p. 94).
\end{abstract}

Sendo assim, a expressão "morador de rua" deve ser evitada, já que o repórter, dificilmente, terá informações suficientes que lhe permitam saber quais dessas pessoas, de fato, não desejam mudar de condições de vida, restituir família e arrumar um emprego. Ou seja, voltar aos padrões socialmente aceitos na sociedade contemporânea.

Ao verificar a maneira como o Clarín, um dos maiores grupos de comunicação da América Latina, trata o assunto das pessoas em situação de rua, verificamos que existe mais cautela e responsabilidade no uso dos termos, como é possível notar na matéria veiculada no dia em que Dilma Rousseff se tornou a primeira presidenta do Brasil:

\footnotetext{
Apenas una hora después de tener los números oficiales, en el centro de Brasilia se presentaba la flamante presidenta electa y establecía en sus palabras los primeros compromisos formales: no descansar hasta terminar con la miseria en Brasil, no dormir en paz mientras haya una sola persona en situación de calle ${ }^{10}$. (Grifo nosso)
}

10 Disponível em: <http://tn.com.ar/internacional/00045004/brasil-dilma-lula-y-lo-que-vendra>. Acesso em: 14 set. 2011. 
No Brasil, o desconhecimento de causa revela-se nos próprios discursos políticos. O ministro da Secretaria-Geral da Presidência da República, Gilberto Carvalho, na mesma ocasião, fez a seguinte declaração:

\begin{abstract}
A presidente Dilma vai lançar a partir do mês que vem [junho] este programa que se chama Combate à Miséria. A nossa ideia é buscar esses 16 milhões de brasileiros que vivem abaixo da linha da miséria para fazer um programa dirigido para essa população. Queremos fazer uma política especial voltada para os catadores de material reciclável, que hoje se organizam em todo o Brasil e já evoluíram muito [...] E o morador de rua, particularmente, que não tem condição especial, ele será objeto de uma política especial nossa de acolhimento", disse o ministro ${ }^{11}$. . (Grifo nosso)
\end{abstract}

Apesar dos exemplos já citados, vale esclarecer que este artigo não pretende generalizar a abordagem sobre o tema realizada pelos meios de comunicação brasileiros que utilizam termos que consideramos inadequados. Apenas procuramos mostrar que alguns veículos adotam posturas diferentes para falar de assuntos iguais. Trata-se de uma minoria, mas que serve de referência aos atuais e futuros profissionais da área.

Exemplo de que nem toda a imprensa brasileira aborda esse assunto com descaso foi uma reportagem publicada no dia 17 de junho de 2012 no Zero Hora, do Rio Grande do Sul, que trazia 16 páginas em um caderno especial e contava a realidade das crianças que vivem nas ruas. "Filho da Rua" foi resultado de três anos de apuração da equipe jornalística, que acompanhou a trajetória de "Felipe", nome fictício dado a um adolescente de 14 anos viciado em crack $^{12}$.

Rezende $(2003)^{13}$ aponta que há, na sociedade, vozes que clamam por uma narrativa do cotidiano que seja mais próxima de suas realidades. De acordo com o autor, quando se trata de uma realidade complexa, o problema é transparente. Ele relata que, em uma de suas entrevistas, encontrou Raimundo Abreu, 38 anos, catador de papel na cidade de Belo Horizonte, que diz que o jornalismo tem "duas linhagens, uma de entretenimento e a outra séria, aquela que a gente não entende". Rezende enfatiza a distância entre o relato jornalístico e a realidade das ruas: "Sr. Nilder, 56 anos,

11 Disponível em: <http://g1.globo.com/politica/noticia/2011/05/dilma-vai-lancar-programa-decombate-miseria-diz-ministro.html>. Acesso em: 14 set. 2011.

12 Disponível em: <http://zerohora.clicrbs.com.br/rs/geral/pagina/filho-da-rua.html>. Acesso em: 19 jun. 2012.

13 Dados coletados pelo autor em entrevistas feitas no período de agosto a dezembro de 2001, na cidade de Belo Horizonte, Brasil. 
entrevistado na Praça 7, região central da mesma cidade, diz que não lê mais jornal, “eles não falam do meu cotidiano"” (REZENDE, 2003, p. 10).

Outra fonte, o Movimento de Meninos e Meninas de Rua, em um seminário, também na cidade de Belo Horizonte, lançou uma carta-documento em que reclama do modo como essas crianças e adolescentes são tratados pela imprensa: "vocês nos intimidam", é o que eles dizem. O autor prossegue (REZENDE, 2003, p. 11): "Não há, a menos que queiramos nos manter encastelados, como deixar de escutar este outro que nos fala".

Felizmente, há outros exemplos de fazeres jornalísticos embasados em princípios de ética e responsabilidade. Repórteres, imbuídos de responsabilidade, humanizam seus relatos e aproximam o público de realidades, muitas vezes, desconhecidas. É o caso do jornalista Mauri König, repórter especial da Gazeta do Povo que, em 22 anos de carreira, recebeu 23 prêmios de jornalismo ${ }^{14}$.

Como a exploração sexual é um tema recorrente quando se trata de vida nas ruas, o repórter tem tratado também dos problemas que envolvem as pessoas em situação de rua, utilizando, inclusive, o termo adequado para se referir a essa população. $\mathrm{Na}$ reportagem "Rede prova ser possível resgatar as vítimas da prostituição"15 (publicada no Jornal de Londrina, do grupo Gazeta do Povo), König aborda a realidade de adolescentes submetidos à exploração sexual em Fortaleza, no Ceará, e destaca dois assuntos principais: o trabalho em equipe realizado por profissionais engajados e os eficientes programas que abrem novas perspectivas, retirando os jovens da rua e da prostituição.

Em 1986, um grupo voluntarioso começou a fazer incursões pela periferia de Fortaleza atrás de crianças em situação de rua. Mapeou os pontos de maior concentração e passou a fazer visitas domiciliares, estreitou uma relação de confiança e traçou com as famílias um projeto de vida para os filhos. Levava esperança, noções de cuidados pessoais e uma proposta de qualificação profissional. Anos mais tarde, em 2008, um novo problema bateu à porta. Desde então, a Associação Barraca da Amizade passou a trabalhar com

\footnotetext{
${ }^{14}$ Mauri König publicou, em 2008, o livro "Narrativas de um correspondente de rua", finalista do Prêmio Jabuti. Em 2003, ganhou o título de Jornalista Amigo da Criança, concedido pela Rede Andi. Atualmente, König e o fotojornalista Albari Rosa estão em produção de reportagem vencedora do último Prêmio Tim Lopes de Jornalismo, viajando pelo país, para cruzar os investimentos públicos em infraestrutura para as cidades-sede da Copa do Mundo de 2014 com os investimentos em prevenção à exploração sexual comercial de crianças e adolescentes no mesmo período.

${ }^{15}$ Disponível em: $<$ http://www.jornaldelondrina.com.br/cidades/conteudo.phtml?tl=1\&id=1294566\&tit=Rede-prova-serpossivel-resgatar-as-vitimas-da-prostituicao>. Acesso em: 8 set. 2012.
} 
vítimas e potenciais vítimas da exploração sexual infanto-juvenil. (Grifo $\operatorname{nosso}^{16}$ )

A reportagem, embora situe a problemática no contexto geral, é centrada no relato do personagem "Leonardo", que recebeu esse nome fictício. König foi sensível à sua condição de ex-michê, e protegeu a sua identidade, afinal, conforme escreveu o repórter: "Leonardo é um bom exemplo de como dá para salvar vidas com políticas públicas quando um governo concede ao assunto a devida importância. Ele, dito por ele mesmo, um sobrevivente das ruas" ${ }^{17}$. O rapaz se tornou aliado dos educadores sociais no resgate de crianças e adolescentes submetidos à exploração sexual.

A seguir, uma análise sobre outras abordagens da mídia sobre o tema.

\section{Análise de dois casos veiculados na Rede Globo}

Neste trabalho, analisamos dois casos veiculados na Rede Globo. O método adotado foi a análise de conteúdo que, conforme Shoemaker \& Reese (1996), ajuda-nos a entender um pouco mais sobre quem produz e quem recebe a notícia e também a estabelecer alguns parâmetros culturais implícitos e a lógica organizacional por trás das mensagens.

Em abril de 2011, o Brasil ficou comovido com a história amplamente divulgada na televisão sobre um catador de materiais recicláveis que encontrou um bebê abandonado pela mãe, em Praia Grande, no litoral paulista. Tratava-se de Andrey Antunes Cotrin, um homem que trabalhou a vida inteira e que estava vivendo nas ruas em consequência de uma depressão, depois de perder o emprego e se separar da esposa. Mesmo juntando latinhas de alumínio para vender, não tinha condições de pagar o aluguel de uma casa e, por isso, estava dormindo debaixo de passarelas e viadutos. Procurado na época pela equipe de reportagem da Rede $G l o b o^{18}$, relatou que se sentia muito feliz por ter salvado a criança e que seu maior desejo era uma "segunda chance". Disse ainda que nunca quis ter chegado àquele ponto de ficar nas ruas.

\footnotetext{
${ }^{16}$ Ibidem.

17 Ibidem.

18 Disponível em: <http://fantastico.globo.com/Jornalismo/FANT/0,,MUL1660743-15605,00.html>. Acesso em: 12 set. 2011.
} 
Nas imagens das câmeras de vigilância que captaram o momento em que o homem resgatou o bebê do lixo, podemos notar que ele não estava maltrapilho e que remexia os entulhos na busca de material reciclável para vender, o que se configura como uma forma de subsistência. O ex-bilheteiro de rodoviária, que tinha como hobby ler dicionários, foi nominado erroneamente quando alguns veículos de comunicação lançaram matérias com títulos como "Morador de rua encontra recém-nascido em caçamba de entulho"19. Esse é apenas um exemplo de como a mídia emprega termos para classificar a população de rua sem antes fazer uma reflexão acerca de seus significados. Nesse caso, a apuração jornalística não contextualizou a vida da pessoa que salvou a vida daquela criança. O pedido de "segunda chance" do protagonista do relato não originou um desdobramento da pauta.

Outro exemplo de um fato que poderia render uma grande reportagem e foi, rasteiramente, noticiado em um dos principais telejornais brasileiros aconteceu em setembro de 2011, em Belém/PA. Uma mulher foi espancada por seguranças de um supermercado e um cinegrafista amador filmou a cena. A notícia foi veiculada e ocupou apenas 13 segundos do Jornal Hoje, da Rede Globo ${ }^{20}$. De acordo com testemunhas, a vítima estava pedindo comida em uma feira quando começaram as agressões.

Levando-se em consideração que o jornalismo desempenha um importante papel social para mobilizar a população e para questionar problemas, pelo menos o viés da falta de moradia ou da especulação do mercado imobiliário poderiam ter sido mencionados ou o caso poderia ter sido o "gancho" para se transformar em uma grande reportagem.

Desta forma, os ideais democráticos - que dizem ser defendidos pela mídia apresentam, na verdade, a carência de um olhar plural, atento às necessidades humanas. O problema das pessoas em situação de rua e os episódios em que essa população está envolvida (geralmente ligados à miséria e à violência) são apresentados pela mídia, geralmente, apenas sob o prisma do fato, sem buscar desdobramentos e possíveis causas.

19 Disponível em:

$<$ http://www.atribuna.com.br/noticias.asp?idnoticia $=89576 \& i d D e p a r t a m e n t o=5 \& i d C a t e g o r i a=7>$. Acesso em: 12 set. 2011.

20 Disponível em: <http://g1.globo.com/jornal-hoje/noticia/2011/09/moradora-de-rua-e-espancada-porsegurancas-em-mercado-de-belem.html>. Acesso em: 8 set. 2011. 
Karam (1997) lembra que a razão humana é mediada pelo conjunto de expressões que se traduz em verbalizações, imagens, memórias, sentimentos, paixões.

O jornalismo deve mostrar tudo isso. Deve mostrar tanto aquilo que 'humaniza' quanto aquilo que 'desumaniza' o homem. Deve mostrar tanto a singularidade do movimento cotidiano dos indivíduos quanto os comportamentos particulares dos grupos e culturas e a conexão universal entre cada indivíduo e o grupo com a totalidade social (KARAM, 1997, p. 94).

Diante desse contexto, podemos afirmar que o jornalismo não pode conviver somente com "as coisas belas da vida", como indica Karam, mas precisa tratar das tragédias que essa mesma vida carrega, para, inclusive, valorizar as consideradas grandiosas. "Os valores sociais só podem ser sentidos tanto pela razão como pela paixão e emoção se estiverem ligados socialmente à diversidade em que se expressam" (1997, p. 78-9). Isso porque há valores universais como o respeito ao outro, que norteiam os fazeres jornalísticos embasados na ética.

Medina (2006) salienta que ao experimentar uma narrativa ao mesmo tempo complexa, afetuosa e poética, "não se escapa dos problemas da crise de paradigmas reducionistas, da crise das percepções, da aridez emocional e da crise das fórmulas aplicadas às rotinas estéticas" (2006, p. 69). De acordo com a autora, a comunhão, a plenitude da comunicação, ocorre na tríplice tessitura de ética, técnica e estética.

\section{Considerações finais}

Salvos os exemplos das reportagens publicadas no Jornal de Londrina e no Zero Hora, as duas notícias veiculadas pela Rede Globo - que serviram de amostragem para a reflexão deste artigo - possibilitam-nos perceber que a grande mídia não costuma tratar a problemática das ruas em sua complexidade. Faz isso, principalmente, quando não apresenta contexto ou quando desumaniza seus protagonistas. Observamos, em diferentes suportes - impresso, on-line, televisivo -, uma falta de interesse em analisar a fundo a história de vida desses personagens que aparecem, quase sempre, nas editorias policiais. 
Os meios de comunicação poderiam atentar ao fato de que os indivíduos podem ser da rua, estar na rua ou ficar na rua, e que designar o termo "moradores de ruas" a todos eles nos parece inadequado. Isso porque, como destaca Soares (2009), a veiculação das representações pelos meios de comunicação tem um inegável impacto na construção social dos significados partilhados, em especial naqueles referentes à construção da democracia.

Por fim, esperamos que este trabalho tenha alguma ressonância social e que, de alguma forma, jornalistas dos veículos de comunicação sintam-se instigados a repensar a forma como relatam situações que envolvem a população em situação de rua.

\section{REFERÊNCIAS}

ALVAREZ, Aparecida; ALVARENGA, Augusta; FERRARA, Nelson. O encontro transformador em moradores de rua na cidade de São Paulo. In: Psicologia \& Sociedade; 16 (3): 47-56; set/dez.2004. Disponível em: <http://www.scielo.br/pdf/psoc/v16n3/a07v16n3.pdf> Acesso em: 15 jun. 2011.

CHAPARRO, Manuel Carlos. Por um jornalismo de pé no chão. Disponível em: <www.comunique-se.com.br>. Acesso em: 13 fev. 2004.

COSTA, Alderon. [17 janeiro 2011]. São Paulo. Entrevista concedida à autora.

CHRISTOFOLETTI, Rogério. Jornalismo, verdade e ética: divulgação científica e confusão informativa. In: LOTH, Moacir (Org.). Comunicando a ciência. Comunicações científicas apresentadas no $6 .^{\circ}$ Congresso Brasileiro de Jornalismo Científico. Florianópolis, SC, ABJC, 2001.

FONTCUBERTA, Mar de; BORRAT, Hector. Periódicos: sistemas complexos, narradores em interação. Buenos Aires: La Crujía, 2006.

GARCÍA CANCLINI, Néstor. Diferentes, desiguais e desconectados: mapas da interculturalidade. Tradução de: HENRIQUES, Luiz Sérgio. 3. ed. Rio de Janeiro: Editora UFRJ, 2009.

IJUIM, Jorge. Humanização e desumanização no jornalismo: algumas saídas. Trabalho apresentado ao DT1 - GP Teorias do Jornalismo no XI Encontro dos Grupos de Pesquisa em Comunicação, evento do XXXIV Congresso Brasileiro de Ciências da Comunicação, Recife, 2011. Disponível em:

<http://www.intercom.org.br/papers/nacionais/2011/resumos/R6-2440-1.pdf>. Acesso em: 23 set. 2011.

KARAM, Francisco José Castilhos. Jornalismo, ética e liberdade. São Paulo: Summus, 1997. 
KOVACH, Bill; ROSENSTIEL, Tom. Os elementos do jornalismo. O que os jornalistas devem saber e o público exigir. Tradução de: DUPONT, Wladir, 2. ed. São Paulo: Geração Editorial, 2004.

LIPPMANN, Walter. Public opinion. New York: Free Press, 1997.

MATTOS, Ricardo Mendes. Situação de rua e modernidade: a saída das ruas como processo de criação de novas formas de vida na atualidade. 2006. 244f. Dissertação (Mestrado) - Programa de Pós-Graduação em Psicologia, Universidade São Marcos, São Paulo, 2006.

MEDINA, Cremilda. Ciência e jornalismo - da herança positivista ao diálogo dos afetos. São Paulo: Summus, 2008.

Paulo: Paulus, 2006.

O signo da relação: comunicação e pedagogia dos afetos. São

RESENDE, Fernando. Ausências na comunicação social e no jornalismo: a lógica da rua. Oficina do CES (197). Coimbra: Centro de Estudos Sociais, novembro de 2003. Disponível em: <http://www.ces.uc.pt/publicacoes/oficina/197/197.pdf>. Acesso em: 12 maio 2012.

SHOEMAKER, Pamela J.; REESE, Sthepen. D. Mediating the message, theories of influences on mass media content. 2. ed. White Plains/NY: Longman, 1996.

SOARES, Murilo César. Representações, jornalismo e a esfera pública democrática. São Paulo: Cultura Acadêmica, 2009.

SOUSA, Jorge Pedro. Teorias da notícia e do jornalismo. Florianópolis: Argos/Letras Contemporâneas, 2002.

TRAQUINA, Nelson. Teorias do jornalismo - porque as notícias são como são. Florianópolis: Insular, 2004.

VIEIRA, Maria Antonieta da Costa; BEZERRA, Eneida Maria Ramos; ROSA, Cleisa Moreno Maffei. População de rua: quem é, como vive, como é vista. São Paulo: Hucitec, 1992. 